was $6 \mathrm{bpm}$ and PCV was $16 \pm 1 \mathrm{bpm}$. The mean nocturnal respiratory rate was $14 \pm 3 \mathrm{bpm}$ and $16 \pm 1 \mathrm{bpm}$ with triggering compliance of $90 \pm 9 \%$ and $24 \pm 10 \%$ for PSV and PCV, respectively. According to the patient-ventilator synchrony questionnaire, patients reported an increased awareness of ineffective efforts $(0.7 \pm 0.5$ vs $0.1 \pm 0.3 ; p=0.03)$ and a short inspiratory time $(0.7 \pm 0.7$ vs $0.1 \pm 0.3 ; p=0.03$ ) during PSV, but there was no difference in self-reported sleep comfort and quality. Furthermore, there were no between group differences in change in $\mathrm{PaCO}_{2}$, ventilator use or nocturnal actigraphy. Although there were similar between group improvements in HROL, the respiratory symptom domain of the Severe Respiratory Insufficiency Questionnaire favoured PSV $(\mathrm{p}=0.02)$.

Conclusion Despite clinicians' perception that PSV has an advantage over PCV for the management of patients with stable hypercapnic COPD, these pilot data do not necessarily support this view.

\section{S67 PHENOTYPIC DIFFERENCES BETWEEN OBESE PATIENTS WITH EUCAPNIC AND HYPERCAPNIC SLEEP-DISORDERED BREATHING (SDB)}

doi:10.1136/thx.2010.150938.18

${ }^{1} \mathrm{~K}$ K Lee, ${ }^{1} \mathrm{E}$ Suh, ${ }^{1} \mathrm{~J}$ Peisch, ${ }^{1} \mathrm{~A}$ McGlone, ${ }^{1} \mathrm{~A}$ Mistry, ${ }^{1} \mathrm{P}$ Murphy, ${ }^{1} \mathrm{~A} J$ Williams, ${ }^{1} \mathrm{~A}$ C Davidson, ${ }^{2} \mathrm{~N}$ Hart. 'Lane Fox Respiratory Unit, Guy's \& St Thomas NHS Foundation Trust, London, UK; ${ }^{2}$ Guy's \& St Thomas NHS Foundation Trust and King's College London NIHR Comprehensive Biomedical Research Centre, London, UK

Background Obesity-related SDB requiring domiciliary non-invasive ventilation (NIV) can present as (1) eucapnic obstructive sleep apnoea (OSA) (2) hypercapnic OSA $\left(\mathrm{P}_{\mathrm{a}} \mathrm{CO}_{2}>6 \mathrm{kPa}\right)$ (3) hypercapnic OSA with obesity hypoventilation syndrome (OHS) and (4) lone OHS. We have adopted the term obesity-related respiratory failure (ORRF) to group these differing conditions. The aim of this study was to determine the clinical features prevalent in each of these conditions in order to guide respiratory management.

Method Data from patients initiated on domiciliary NIV at a tertiary referral unit, between August 2005 and December 2009, were obtained from a purpose-designed discharge summary database. Patients were categorised into four groups, as described above. Comparative analyses were performed between (1) eucapnic OSA and the hypercapnic groups (2) hypercapnic OSA and a group combining the OSA with OHS and the lone OHS groups (OSA \& OHS and lone OHS) and (3) eucapnic and hypercapnic OSA. Logistic regression analysis was performed to determine factors associated with hypercapnia.

Results 163 patients were included in the analyses. Group mean (SD) age $54.3 \pm 14.2$ years, weight $134.4 \pm 33.1 \mathrm{~kg}$, body mass index (BMI) $48.4 \pm 2.5 \mathrm{~kg} / \mathrm{m}^{2}$ and Epworth sleepiness (ESS) score 14.8 \pm 5.8 . Results are shown in Abstract S67 Table 1. The hypercapnic groups demonstrated a higher prevalence of diabetes. In addition, hypercapnic patients were overall, compared with eucapnic patients, more hypoxic with greater lung restriction, despite a non-significant increase in BMI in the hypercapnic OSA group. Compared with the hypercapnic OSA group, the combined OSA and OHS and lone OHS group had a higher BMI, ESS and greater hypercapnia. However, logistic regression analysis failed to demonstrate any factors that predicted hypercapnia.
Abstract S67 Table 1

\begin{tabular}{lllll}
\hline & $\begin{array}{l}\text { Eucapnic OSA } \\
(\mathbf{n}=\mathbf{5 0})\end{array}$ & $\begin{array}{l}\text { Hypercapnic } \\
\mathbf{0 S A}(\mathbf{n}=\mathbf{3 8})\end{array}$ & $\begin{array}{l}\text { OSA+OHS } \\
(\mathbf{n}=\mathbf{6 4})\end{array}$ & $\begin{array}{l}\text { Lone OHS } \\
(\mathbf{n}=\mathbf{1 1})\end{array}$ \\
\hline Male & $36(72)$ & $22(57.9)$ & $29(45.3)^{*}$ & $3(27.3)^{*}$ \\
Age (years) & $50.0 \pm 13.5$ & $56.1 \pm 14.0^{*}$ & $56.1 \pm 13.8^{*}$ & $57.1 \pm 17.4$ \\
Diabetes mellitus & $10(20)$ & $17(48.6)^{*}$ & $32(50.0)^{*}$ & $4(36.4)$ \\
Hypertension & $21(42)$ & $24(66.7)$ & $33(51.6)$ & $5(45.5)$ \\
$\mathrm{BMI}\left(\mathrm{kg} / \mathrm{m}^{2}\right)$ & $44.0 \pm 11.4$ & $46.11 \pm 10.0 \neq$ & $53.72 \pm 13.9^{*} \dagger$ & $48.25 \pm 8.9$ \\
$\mathrm{ESS}$ & $14.2 \pm 6.3$ & $13.1 \pm 5.4 \neq$ & $16.4 \pm 5.0^{*}$ & $12.7 \pm 10.6^{*}$ \\
$\mathrm{FVC}(\mathrm{L})$ & $3.0 \pm 1.1$ & $1.9 \pm 1.0^{*}$ & $1.9 \pm 0.9^{*}$ & $1.5 \pm 0.6^{*}$ \\
$\mathrm{pH}$ & $7.41 \pm 0.02$ & $7.39 \pm 0.03^{*}$ & $7.38 \pm 0.3^{*}$ & $7.39 \pm 0.06$ \\
$\mathrm{PaO}_{2}(\mathrm{kPa})$ & $10.4 \pm 1.6$ & $8.0 \pm 1.5^{*}$ & $8.0 \pm 1.5^{*}$ & $7.8 \pm 1.3^{*}$ \\
$\mathrm{PaCO}_{2}(\mathrm{kPa})$ & $5.4 \pm 0.4$ & $7.0 \pm 0.7^{*} \neq$ & $7.6 \pm 1.3^{*} \dagger$ & $7.9 \pm 1.2^{*} \dagger$ \\
$\mathrm{HCO}{ }_{3}^{-}(\mathrm{mmo} / \mathrm{l})$ & $25.2 \pm 1.9$ & $30.8 \pm 3.0^{*}$ & $33.0 \pm 4.5^{*} \dagger$ & $33.5 \pm 5.2 \dagger$ \\
Length of stay (days) & $2.6 \pm 2.8$ & $4.3 \pm 2.7^{*}$ & $5.1 \pm 4.2^{*}$ & $6.5 \pm 6.0^{*}$ \\
1 -year mortality & $0(0)$ & $1(2.6)$ & $2(3.1)$ & $1(9.1)$ \\
\hline
\end{tabular}

Data presented as $\mathrm{n}(\%)$ or mean $\pm \mathrm{SD}$.

OSA, obstructive sleep apnoea; OHS, obesity hypoventilation syndrome; BMI, body mass index; ESS, Epworth sleepiness score; FVC, forced vital capacity.

*Significant difference compared to eucapnic OSA group.

†Significant difference compared to hypercapnic OSA group.

$\ddagger$ Significant difference between hypercapnic OSA group and combined group of OSA $+\mathrm{OHS}$ and lone OHS

Conclusion Demographic, anthropometric, spirometric and clinical features allow the different ORRF conditions to be distinguished. BMI, daytime symptoms and degree of chronic respiratory failure distinguished between hypercapnic OSA from obesity-related hypoventilation. Although we hypothesise that ORRF is a disease spectrum, from eucapnic OSA progressing to hypercapnic OSA to OSA with OHS, we were unable to identify factors that predicted hypercapnia. From these data, we propose that more detailed physiological assessment, including neural respiratory drive and pulmonary mechanics, is required.

\section{S68 EVALUATION OF NON-INVASIVE VENTILATION IN MANAGEMENT OF ACUTE SEVERE ASTHMA}

doi:10.1136/thx.2010.150938.19

D Chaudhry, M Indora, V Sangwan, I P S Sehgal, A Chaudhry. Pandit BDS Post Graduate Institute of Medical Sciences, Rohtak, India

Objectives To study the role of non-invasive positive pressure ventilation (NIPPV) in management of acute severe asthma.

Study design Open randomised controlled trial.

Methods 50 patients of acute severe asthma having asthma for at least 1 year duration with exacerbation of less than 7 days duration, FEV1 $<50 \%$ of predicted, respiratory rate of $>25$ breaths $/ \mathrm{min}$ and pulse rate $>110 / \mathrm{min}$ after half hour of $5 \mathrm{mg}$ nebulised salbutamol were included in the study over 1 year. Patients with known COPD, history of smoking $>10$ years, HR $>140 / \mathrm{min}$, systolic BP $<90 \mathrm{~mm}$ $\mathrm{Hg}$, facial deformity, pulmonary oedema, pneumonia and pregnancy were excluded. Patients were divided into two groups A and B. All patients received nebulisation with salbutamol $5 \mathrm{mg}$ and ipratropium bromide $0.5 \mathrm{mg}$ and hydrocortisone $100 \mathrm{mg}$ IV at zero hour and later $5 \mathrm{mg}$ salbutamol with small volume oxygen driven nebuliser@61/min at 1,2,3,5 h of the study. Group B patients were given NIV support in addition to medical therapy for $6 \mathrm{~h}$. All patients received $\mathrm{O}_{2}$ at $6-8 \mathrm{l} / \mathrm{min}$ for $6 \mathrm{~h}$. NIV and medical treatment were stopped after $6 \mathrm{~h}$. Spirometry, ABG, respiratory rate (RR), accessory muscles of respiration (AMR) and Borg dyspnoea score were assessed at $0,1,3,6$ and 7 th hour of study.

Results Out of 308 patients 246 were excluded because of nonfulfilment of inclusion criteria. Eight patients refused consent, three had pneumonia and claustrophobia to mask respectively. One 